EL ANTONIANO. 2020; 135: 61-67

Recepción: 15-11-2017

Aprobación: 20-01-2020

\title{
MORFOLOGIA INTERNA DEL CONDUCTO RADICULAR DEL PRIMER PREMOLAR SUPERIOR SEGÚN LA TOMA RADIOGRAFICA Y TECNICA DE DIAFANIZACION, CUSCO- 2017
}

Vargas Gonzales; Yahaira Paola yahaira.vargas@unsaac.edu.pe

Nieto Muriel; Miguel Ángel

Ticona Mandujano; Milton J.

\section{RESUMEN}

La morfología de los conductos radiculares es bastante compleja; oculta muchos detalles que son difíciles o en ocasiones imposibles de percibir mediante el uso de técnicas convencionales como la radiografía periapical. Objetivo.- determinar la morfología del conducto radicular según la toma radiográfica y la técnica de diafanización. Materiales y métodos.- Estudio descriptivo, cuya muestra estuvo constituida por 30 primeros premolares superiores y se utilizó la clasificación de Vertucci para determinar la presencia de conductos laterales y deltas apicales. Resultados.- predomino el tipo I tanto en toma radiográfica como en muestras diafanizadas, no encontrándose los tipos III, V, VII ni VIII; se encontró un 53\% de acuerdo entre radiografía y diafanización; hubo 3 conductos laterales en tomas radiográficas y 7 en muestras diafanizadas, finalmente se identificó 1 delta apical en toma radiográfica y 2 en muestras diafanizadas, obteniendo un resultado general de $73 \%$ de concordancia entre toma radiográfica y muestras diafanizadas.

Palabras Clave: Morfología interna, radiografía periapical, conducto radicular, clasificación de Vertucci.

\begin{abstract}
The morphology of the root canals is quite complex; hides many details that are difficult or sometimes impossible to perceive through the use of conventional techniques such as periapical radiography. Objective.- To determine the morphology of the root canal according to the radiographic taking and the diafanization technique. Materials and methods.- Descriptive study, whose sample consisted of the first 30 upper premolars and the Vertucci classification was used to determine the presence of lateral ducts and apical deltas. Results.- Type I predominated in both radiographic and diafanized samples, with types III, V, VII and VIII not being found; 53\% agreement was found between
\end{abstract}


radiography and diafanization; There were 3 lateral ducts in radiographic shots and 7 in diafanized samples, finally 1 apical delta was identified in radiographic sampling and 2 in diafanized samples, obtaining a general result of $73 \%$ concordance between radiographic sampling and diafanized samples.

Keywords: Internal morphology, periapical radiography, root canal, Vertucci classification.

\section{INTRODUCION}

La radiografía periapical es el método de ayuda diagnóstica más común del que se dispone en nuestro medio, por estar al alcance de casi todos los pacientes en términos económicos, aportando datos clínicos de suma importancia como son número de conductos, conformación de cámara pulpar y otros. (1) Siendo su principal inconveniente la falta de objetividad acerca de estructuras muy pequeñas o la superposición de imágenes, pudiendo dar una información en ocasiones equivocada, así la información que provee se presenta en solo dos dimensiones. (2)

Actualmente se sabe que existen múltiples variantes dentro del conducto radicular, las variantes que se encuentran en mayor porcentaje según estudios realizados vienen encabezados por los conductos laterales y deltas apicales, teniendo a la clasificación de Vertucci como claro ejemplo.(3) Así mismo; una de las piezas que más variantes presentan en su anatomía consiste en los primeros premolares superiores y es por ello que mediante la tinción y diafanización de las piezas se pretende observar la morfología interna que presentan.(4)

\section{MATERIALES Y METODOS.-}

Estudio tipo Descriptivo, transversal, cuya muestra estuvo constituida por 30 piezas premolares superiores, el tipo de muestreo fue no probabilístico intencional; dentro de los criterios de selección se consideró piezas dentales con foramen apical totalmente desarrollado y piezas dentales con lesiones cariosas que no comprometan la zona radicular. Se utilizó la técnica de campo que nos permitió la observación en contacto directo con el objeto de estudio, que nos permitió confrontar la teoría con la práctica en la búsqueda de la verdad objetiva. La recolección de la muestra se realizó en dos tiempos, inicialmente se realizó la toma radiográfica y posteriormente se realizó la técnica de diafanización. 
RESULTADOS.- 
CUADRO $\mathbf{N}^{\circ} 1$

MORFOLOGIA INTERNA DEL CONDUCTO RADICULAR SEGÚN TOMA

RADIOGRAFICA Y DIAFANIZACION

\begin{tabular}{l|l|c|c|c|c}
\hline \multicolumn{2}{c|}{ Dimensión } & \multicolumn{2}{c|}{$\begin{array}{c}\text { Vista en toma } \\
\text { radiográfica }\end{array}$} & \multicolumn{2}{c}{$\begin{array}{c}\text { Muestra } \\
\text { diafanizadas }\end{array}$} \\
\cline { 3 - 6 } Indicadores & Tipo I & 14 & $46.6 \%$ & 15 & $50 \%$ \\
\hline \multirow{3}{*}{ Conducto principal } & Tipo II & 11 & $36.6 \%$ & 4 & $13.3 \%$ \\
\cline { 2 - 7 } & Tipo IV & 3 & $10 \%$ & 8 & $26.6 \%$ \\
\cline { 2 - 7 } & Tipo VI & 2 & $6.6 \%$ & 3 & $10 \%$ \\
\hline Conductos laterales & Presente & 7 & $23.3 \%$ & 3 & $10 \%$ \\
\hline Deltas apicales & Presente & 1 & $3.3 \%$ & 2 & $6.6 \%$ \\
\hline
\end{tabular}

$\%$ de acuerdos observados

CUADRO $\mathbf{N}^{\circ} 2$

CLASIFICACION DEL CONDUCTO PRINCIPAL SEGÚN ESCALA DE VERTUCCI EN TOMA RADIOGRAFICA Y MUESTRAS DIAFANIZADAS

\begin{tabular}{l|r|r|r|r}
\hline & \multicolumn{5}{|c}{ Conducto principal } \\
\cline { 3 - 6 } \multicolumn{1}{c|}{ Indicador Dimensión } & Tipo I & Tipo II & Tipo IV & Tipo VI \\
\hline Vista en toma radiográfica & 14 & 11 & 3 & 2 \\
\hline Muestra diafanizadas & & & & \\
& 15 & 4 & 8 & 3 \\
\hline
\end{tabular}

\begin{tabular}{lr}
\hline $\mathbf{n}^{\circ}$ de casos & 30 \\
\hline Acuerdos observados & 16 \\
\hline \% de acuerdos observados & $53 \%$ \\
\hline valor-p & 0.027 \\
\hline Kappa de Cohen & 0.682 \\
\hline
\end{tabular}


CUADRO $\mathrm{N}^{\circ} 3$

APRECIACION DE CONDUCTOS LATERALES SEGÚN TOMA

RADIOGRAFICA Y DIAFANIZACION

\begin{tabular}{l|c|c}
\hline \multirow{2}{*}{ INDICADOR } & \multicolumn{2}{|c}{ Conductos Laterales } \\
\cline { 2 - 3 } DIMENSION & Ausencia & Presente \\
\hline Vista en toma radiográfica & 27 & 3 \\
\hline Muestra diafanizadas & 23 & 7 \\
\hline
\end{tabular}

\begin{tabular}{l|r}
\hline $\mathbf{n}^{\circ}$ de casos & 30 \\
\hline Acuerdos observados & 22 \\
\hline$\%$ de acuerdos observados & $73 \%$ \\
\hline valor-p & 0.666 \\
\hline Alfa & 0.05 \\
\hline Kappa de Cohen & 0.785 \\
\hline
\end{tabular}

CUADRO $\mathbf{N}^{\circ} 4$

APRECIACION DE DELTAS APICALES EN TOMA RADIOGRÁFICA Y MUESTRAS DIAFANIZADAS

\begin{tabular}{l|r|r}
\hline \multirow{2}{*}{ INDICADOR } & \multicolumn{2}{|c}{ Deltas Apicales } \\
\cline { 2 - 3 } DIMENSION & Ausencia & \multicolumn{2}{|c}{ Presente } \\
\hline Vista en toma radiográfica & 29 & 1 \\
\hline Muestra diafanizadas & 28 & 2 \\
\hline
\end{tabular}

\begin{tabular}{l|r}
\hline $\mathbf{n}^{\circ}$ de casos & 30 \\
\hline Acuerdos observados & 27 \\
\hline \% de acuerdos observados & $90 \%$ \\
\hline valor-p & 0.786 \\
\hline Kappa de Cohen & 0.795 \\
\hline
\end{tabular}




\section{CONCLUSIONES}

1.- Existe un predominio del tipo I de Vertucci, seguido del tipo II en vista radiográfica y tipo IV en muestras diafanizadas; no se encontraron los tipos III, V, VII y VIII según clasificación de Vertucci tanto en radiografías como en muestras diafanizadas

2.- Hubo una buena concordancia entre toma radiográfica y las muestras diafanizadas

\section{REFERENCIAS BIBLIOGRAFICAS}

1. Urzúa R. Tecnicas Radiograficas Dentales y Maxilofaciales Aplicaciones Caracas - Venezuela: AMOLCA; 2005.

2. Oviedo Muñoz PC. Tomografia Cone Beam Aplicado a la Endodoncia Lima; 2010.

3. Estrela C. Ciencia Endodontica. 1st ed. Sao Paulo - Brasil: Artes Medica Latinoamerica; 2005.

4. LLamosas Hernandez E, Rosas Gonzales G, Pujana Garcia Salmones J. Estudio descriptivo de los conductos laterales de los dientes permanentes. Revista de la
Asociacion Dental Mexicana. 2005 Enero - Febrero; 62(1).

5. B. AT. Anatomia interna de conductos radiculares premolares superiores, estudio mediante tecnica de diafanizacion. 2015.

6. Canalda. C, Brau E. Endodoncia técnicas clinicas y bases cientificas Barcelona: ELSEVIER.; 2014.

7. Covo Morales E, Gonzales Martinez F, Zabalera Garces G, Arbelaez Florez M. Validez y confiabilidad de dos tecnicas radiograficas para la identificacion de conductos radiculares. Revista CES Odontologia - Articulos de Investigacion Cientifica yTecnologica. 2013 Junio; 26(1).

8. De Lima M. Anatomia Interna externa y macroestructuras dentarias Endodoncia de la biologia a la tecnica Sao Paulo - Brasil: AMOLCA; 2009.

9. Cobos Parra D, Moscoso Abad M. Estudio Morfologico de los Canales Radiculares del Primer Premolar Suprior, utilizando radiografia periapical y tomografia de haz conico, en el Centro Radiologico Dental - Maxilofacial, Cuenca 2015. Odontologia Activa UCACUE. 2016 Enero; 1(1). 
10. Canto Franco P, Saraya Jean S, Suarez Martinez de Arredondo AC,

Torres Zavala M. Morfologia Del Conducto Radicular En Premolares. 2012. 